\title{
Intraoperative Use of Analgesics in Tonsillar Fossa and Postoperative Evaluation with Visual analogue Scale Scores-A Prospective, Randomized, Placebo- Controlled, Double-Blind Clinical Trial
}

\author{
Montasir Junaid ${ }^{10}$ Muhammad Sohail Halim² Maisam Abbas Shiraz Onali ${ }^{3} \quad$ Sadaf Qadeer ${ }^{4}$ \\ Hareem Usman Khan ${ }^{5}$ Naeem Sultan Ali $^{6}$
}

${ }^{1}$ Department of Otolaryngology-Head and Neck Surgery, Armed Forces Hospital Southern Region, Khamis Mushayt, Saudia Arabia

2 Byers Eye Institute, Stanford University, Palo Alto, CA, United States

${ }^{3}$ Department of Otorhinolaryngology-Head and Neck Surgery, Jinnah Medical College and Hospital, Karachi, Pakistan

${ }^{4}$ Department of Otorhinolaryngology-Head and Neck Surgery, Sir

Syed College of Medical Sciences for girls, Karachi, Pakistan

${ }^{5}$ Department of Cardiology, Shifa Intersternal Hospital, Islamabad, Pakistan

${ }^{6}$ Department of Otolaryngology-Head and Neck Surgery, The Aga

Khan Hospital, Dar-es-salaam, Tanzania

\begin{abstract}
Address for correspondence Dr. Montasir Junaid, MBBS, FCPS, Department of Otolaryngology-Head and Neck Surgery, Armed Forces Hospital Southern Region, P.O Box: 101, Khamis Mushayt, 61961, Saudia Arabia (e-mail: montsj@gmail.com).
\end{abstract}

Int Arch Otorhinolaryngol 2020;24:e62-e67.

\begin{abstract}
Introduction Posttonsillectomy pain results in significant morbidity to the patients. There is a disagreement in the literature regarding the use of local anesthetics during tonsillectomy. The aim of this placebo-controlled, double-blind study is to evaluate the effect of peritonsillar administration of local anesthetics.

Objective To evaluate the role of intraoperative use of analgesics in tonsillar fossa and postoperative evaluation with visual analogue scale (VAS) scores in achieving pain relief after tonsillectomy procedure

Methods In this study, 180 patients were randomized to 1 of the 6 groups: bupivacaine infiltration, lidocaine infiltration, normal saline infiltration, bupivacaine packing, lidocaine packing, and normal saline packing. Pain caused by speaking, swallowing, and on rest was assessed using VAS at 4, 8, 12, 16 hours, and at discharge. Results Significant analgesia was obtained in patients who received bupivacaine infiltration and packing compared with placebo $(p<0.05)$. The majority of the study

Keywords

- tonsillectomy

- pain

- analgesia subjects had no postoperative complications, and patients receiving bupivacaine infiltration required less additional analgesics in the first 24 hours after surgery. Conclusion We advocate the use of bupivacaine infiltration or packing immediately following the procedure to achieve adequate postoperative analgesia.
\end{abstract}

\section{Introduction}

Postoperative analgesia is a vital part of therapy in patients undergoing tonsillectomy. Considering that tonsillectomy is one of the most common otolaryngology procedures, ade-

received

November 24, 2018

accepted

February 17, 2019
DOI https://doi.org/

10.1055/s-0039-1684037. ISSN $1809-9777$. quate postoperative analgesia is essential to decrease morbidity in patients. ${ }^{1,2}$ The pain peaks immediately after procedure and sustains for the initial three postoperative days. $^{3}$ Thus, a need of adequate postoperative analgesia is warranted. ${ }^{1,3,4}$
Copyright $\odot 2020$ by Thieme Revinter

Publicações Ltda, Rio de Janeiro, Brazil
License terms

c) $(1) \$$ 
Various practices have been described in the literature to achieve adequate pain control, decrease morbidity, and enhance recovery after tonsillectomy. These include preoperative topical administration of local anesthetics, nerve blockade, use of dexamethasone, opioids, acetaminophen, nonsteroidal antiinflammatory drugs (NSAIDs), perioperative hydration, family education, and different surgical approaches. ${ }^{1,2,4-6}$ Systemic analgesics and opioids provide pain relief, but this therapy is associated with increase in postoperative nausea, vomiting and constipation, which can lead to decreased oral intake and dehydration. The alternative is to use a local anesthetic agent to achieve adequate pain control.

Bupivacaine is a potent analgesic that produces rapid and sustained analgesia. ${ }^{7-9}$ It has been used as a peripheral nerve block and for prevention of postoperative pain following tonsillectomy. ${ }^{10-13}$ Lidocaine is a common local anesthetic agent that is widely used. Lidocaine has been utilized in management of posttonsillectomy pain. ${ }^{14,15}$ Local infiltration of local anesthetic agents in the tonsillar fossa is known to produce complications due to inadvertent intravascular injection, ${ }^{16}$ whereas topical application is considered safe and simple to perform.

Pre and postoperative local anesthetic agents like bupivacaine and lignocaine have been utilized in the literature as infiltration in the tonsillar fossa with conflicting results. However, due to the scarcity of data on the effect of local anesthetic agents on posttonsillectomy pain control, we aimed to evaluate the role of local anesthetic agents, in injectable and topical form, in achieving adequate pain relief after the tonsillectomy procedure.

\section{Methodology}

\section{Study Design}

This prospective, randomized, double-blind clinical trial was conducted at a tertiary care hospital in Karachi, Pakistan, over a period of 3 years (Jan 2012-Dec 2015). Institutional ethical review committee approval and informed written consent were obtained prior to the enrollment. A minimal sample size calculation showed 13 patients to be recruited in each arm of the study, but to bring the sample size to a normal distribution 30 participants in each arm were enrolled. Thus, a total of 180 patients were recruited for the purpose of this study.

\section{Randomization and Intervention}

Patients were presented with six unidentified papers to choose from with preassigned codes for each group. Patients were randomized to one of the six (6) therapies: bupivacaine infiltrate, lidocaine infiltrate, normal saline infiltrate, bupivacaine pack, lidocaine pack, and normal saline pack. Each group had 30 patients. A clinical nurse was assigned to prepare the codes and for infiltration or pack and, then, to provide it to the operating surgeon in an unlabeled sealed envelope before the procedure. Since all the analgesic agents were clear liquids, there was no way for the surgeon or patient to know which agent $u$ placed in the envelope. The infiltration or pack was administered at the completion of surgery, just before extuba- tion. No patient was given systemic analgesics in the first 24 hours after surgery. Two (2) ward nurses were trained to ask about the visual analogue scale (VAS) scores from patients at different intervals $(4,8,12$ and 16 hours postoperatively) until the time they were discharged. These findings were noted in a separate questionnaire. (See - Proforma - available online) All patients were operated with diathermy to minimize confounders in the study.

\section{Patient Eligibility}

Patients undergoing elective tonsillectomy at a tertiary care hospital in Karachi, Pakistan, were eligible for the study. Ability to provide a signed informed consent by the patient or guardian/parent was a requirement to be eligible in the study.

\section{Outcome Measures}

Change in pain, dysphagia, and difficulty in speaking and at rest as assessed by the VAS at various time intervals following surgery.

\section{Masking}

This study was a double-masked study: both the operating surgeon and the patients were not aware of the treatment dose they had been assigned to.

\section{Statistical Analysis}

Data were stored and analyzed using the software Stata version 14.2 (StataCorp. LP, College Station, TX, USA). Count and percentages were reported for all baseline study parameters, mean and standard deviation were also reported for quantitative parameters. The Pearson Chi-square test was used to see the association of infiltration with postoperative analgesics and frequency; a bar chart was also used to display the graphical summary of results.

To compare the VAS scores from 4 hours to discharge for speaking, swallowing, and rest, a generalized linear model with repeated measures designed was used to see the effect of the topical use of analgesics, postoperative analgesics (primary and secondary) and their frequencies in 24 hours. A further posthoc analysis was performed to compare the VAS scores across different levels, and $p$-values $<0.05$ were considered significant. Trend charts also reported to see observed the behavior of VAS scores for different factors at different levels.

\section{Results}

One hundred and eighty (180) patients underwent tonsillectomy and were included in this study in the 5-year period between 2012 and 2016. The mean age of the study participants was 14.6 years. A total of $53.9 \%$ of the participants were male. (-Table 1) All patients received preoperative antibiotics. The intraoperative time for the majority of the patients (59.4\%) was between 11 and 20 minutes. The intraoperative blood loss was 1 to $5 \mathrm{ml}$ in $44.4 \%$ patients.

The majority of the patients received intravenous (IV) coamoxiclav (79.4\%) in the immediate postoperative period. Paracetamol IV was most frequently (98.3\%) used in the 
Table 1 Baseline characteristics of the study population

\begin{tabular}{|l|l|l|l|}
\hline \multicolumn{2}{|l|}{ Characteristics } & Mean & SD \\
\hline Age (years) & & 14.58 & 7.49 \\
\hline \multirow{3}{*}{ Gender } & Male & $\mathbf{n}$ & $\%$ \\
\cline { 2 - 4 } & Female & 97 & 53.9 \\
\hline Preoperative antibiotics & co-amoxiclav & 143 & 46.1 \\
\cline { 2 - 4 } & clarithromycin & 26 & 79.4 \\
\cline { 2 - 4 } & ceftriaxone & 11 & 6.1 \\
\hline Time taken for surgery & $<10$ minutes & 68 & 37.8 \\
\cline { 2 - 4 } & $11-20$ minutes & 107 & 59.4 \\
\cline { 2 - 4 } & $20-30$ minutes & 5 & 2.8 \\
\hline Blood loss (mL) & $0 \mathrm{~mL}$ & 65 & 36.1 \\
\cline { 2 - 4 } & $1-5 \mathrm{~mL}$ & 80 & 44.4 \\
\cline { 2 - 4 } & $5-10 \mathrm{~mL}$ & 35 & 19.4 \\
\hline
\end{tabular}

Abbreviation: SD, standard deviation.

postoperative period, with the need of IV analgesia being more than 3 times higher in $54.44 \%$ of the patients. Approximately $30 \%$ of the patients required a second analgesic for adequate pain relief. The most common intraocular complication was secondary hemorrhage $(7.78 \%)$ followed by infection (5.0\%). (-Table 2) There was an overall statistical difference in the postoperative complications and study groups $(p=0.009)$. However, the difference in the rate of procedurerelated postoperative complications among the six study groups was not statistically significant $(p=0.86)$. All 6 patients in the study who had transient cardiac arrhythmia belonged to the bupivacaine infiltrate group. A total of $93.9 \%$ of the patients received antibiotics at discharge, while almost all of the patients received oral analgesics with $18.9 \%$ requiring a second analgesic for adequate pain relief. (-Table 3) Approximately 40\% of the patients in both placebo groups required a second analgesic for pain relief, while only $7 \%$ of the patients in the bupivacaine infiltrate group needed a second analgesic in the postoperative period.

Mean VAS scores for dysphagia, difficulty in speaking, and pain at rest of patients belonging to bupivacaine infiltrate and bupivacaine pack were significantly lower $(p<0.01)$ when compared with the other groups, at 4, 8, 12 and 16 hours postoperatively. - Figs. 1-3 show the trends of VAS for speaking, swallowing, and pain at rest at various time points after the surgery. The overall mean VAS score for difficulty in speaking, swallowing, and pain at rest was the lowest in the bupivacaine infiltrate group $(1.74,1.73$, and 1.37 respectively) and the highest in the normal saline group (-Table 4). The accumulated mean VAS score for dysphagia, difficulty in speaking, and pain at rest was the highest in the placebo group. The difference in mean VAS score among the study groups was statistically significant $(p<0.05)$.

The general linear model (GLM)-repeated measure of analysis of variance (ANOVA) demonstrated that infiltration has a significant impact on the VAS scores from 4-hours to
Table 2 Postoperative characteristics of the patients

\begin{tabular}{|c|c|c|c|}
\hline \multicolumn{2}{|l|}{ Characteristics } & \multirow{2}{*}{$\frac{n}{143}$} & \multirow{2}{*}{$\begin{array}{l}\% \\
79.4\end{array}$} \\
\hline Postoperative & IV co-amoxiclav & & \\
\hline & IV clarithromycin & 26 & 14.4 \\
\hline & IV ceftriaxone & 11 & 6.1 \\
\hline \multirow{2}{*}{$\begin{array}{l}\text { Postoperative } \\
\text { analgesics }\end{array}$} & IV paracetamol & 177 & 98.3 \\
\hline & Not prescribed & 3 & 1.67 \\
\hline \multirow{4}{*}{$\begin{array}{l}\text { Frequency of } \\
\text { postoperative } \\
\text { analgesia use }\end{array}$} & Once & 17 & 9.44 \\
\hline & Twice & 21 & 11.67 \\
\hline & Thrice & 44 & 24.44 \\
\hline & More than thrice & 98 & 54.44 \\
\hline \multirow{4}{*}{$\begin{array}{l}\text { Postoperative } \\
\text { second } \\
\text { analgesic use }\end{array}$} & IV paracetamol & 1 & 0.56 \\
\hline & IV ketorolac & 45 & 25.00 \\
\hline & IV tramadol & 7 & 3.89 \\
\hline & Not prescribed & 127 & 70.56 \\
\hline \multirow{4}{*}{$\begin{array}{l}\text { Frequency of } \\
\text { postoperative } \\
\text { second } \\
\text { analgesia use }\end{array}$} & Once & 38 & 21.11 \\
\hline & Twice & 13 & 7.22 \\
\hline & Thrice & 2 & 1.11 \\
\hline & More than thrice & 127 & 70.56 \\
\hline \multirow{6}{*}{$\begin{array}{l}\text { Postoperative } \\
\text { complication }\end{array}$} & Primary hemorrhage & 1 & 0.56 \\
\hline & Secondary hemorrhage & 13 & 7.78 \\
\hline & Dehydration & 6 & 3.33 \\
\hline & Infection & 9 & 5.00 \\
\hline & Cardiac arrhythmia & 6 & 3.33 \\
\hline & No complications & 145 & 80.56 \\
\hline
\end{tabular}

Abbreviation: IV, intravenous.

Table 3 Characteristics of patients at discharge

\begin{tabular}{|l|l|l|l|}
\hline Characteristics & $\mathbf{n}$ & $\%$ \\
\hline \multirow{2}{*}{$\begin{array}{l}\text { Antibiotics at } \\
\text { discharge }\end{array}$} & Oral co-amoxiclav & 143 & 79.44 \\
\cline { 2 - 4 } & Oral clarithromycin & 26 & 14.44 \\
\cline { 2 - 4 } & Not prescribed & 11 & 6.11 \\
\hline \multirow{2}{*}{$\begin{array}{l}\text { Analgesics at } \\
\text { discharge }\end{array}$} & Oral paracetamol & 100 & 55.56 \\
\cline { 2 - 4 } & Oral ibuprofen & 78 & 43.33 \\
\cline { 2 - 4 } & Not prescribed & 2 & 1.11 \\
\hline \multirow{2}{*}{$\begin{array}{l}\text { Second analgesic } \\
\text { use at discharge }\end{array}$} & Yes & 34 & 18.89 \\
\cline { 2 - 4 } & No & 146 & 81.11 \\
\hline
\end{tabular}

discharge follow-up; postoperative analgesia and its frequency did not have any significant impact, but secondary postoperative analgesia and its frequency showed a significant impact on difficulty in speaking on the VAS. Similarly, infiltration, secondary postoperative analgesia and its frequency had significant impact on difficulty in speaking on the VAS $(p<0.05)$. All other combinations were found statistically insignificant $(p>0.05)$. Infiltration, secondary postoperative analgesic and its frequency showed significant impact on pain at rest VAS results. 


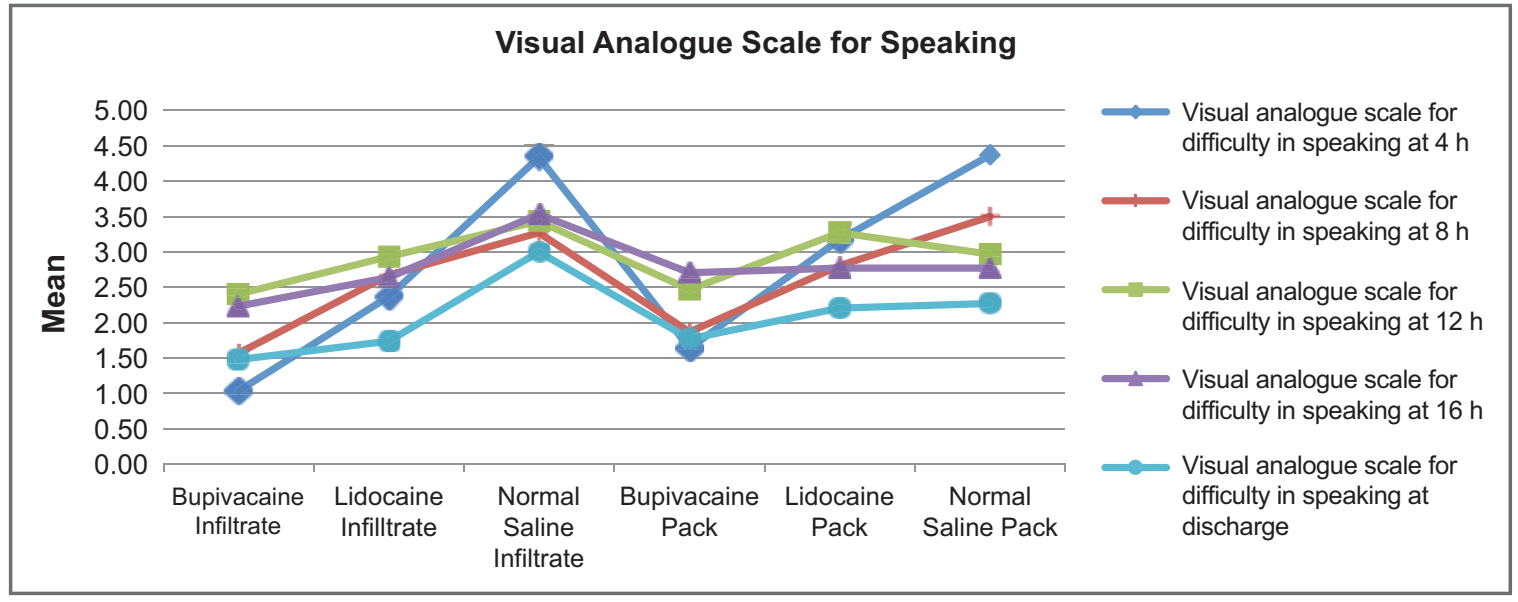

Fig. 1 Visual analogue scale for difficulty in speaking.

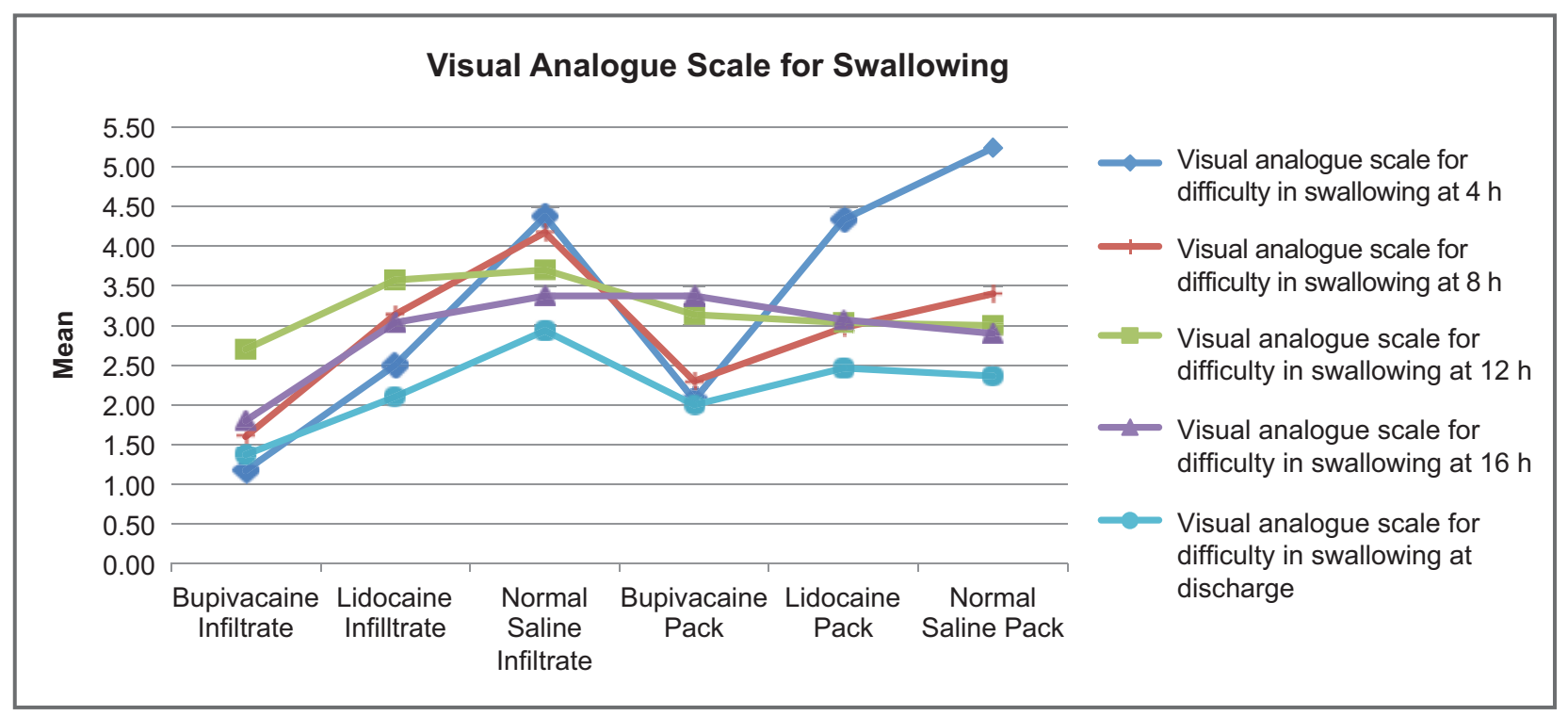

Fig. 2 Visual analogue scale for difficulty in swallowing.

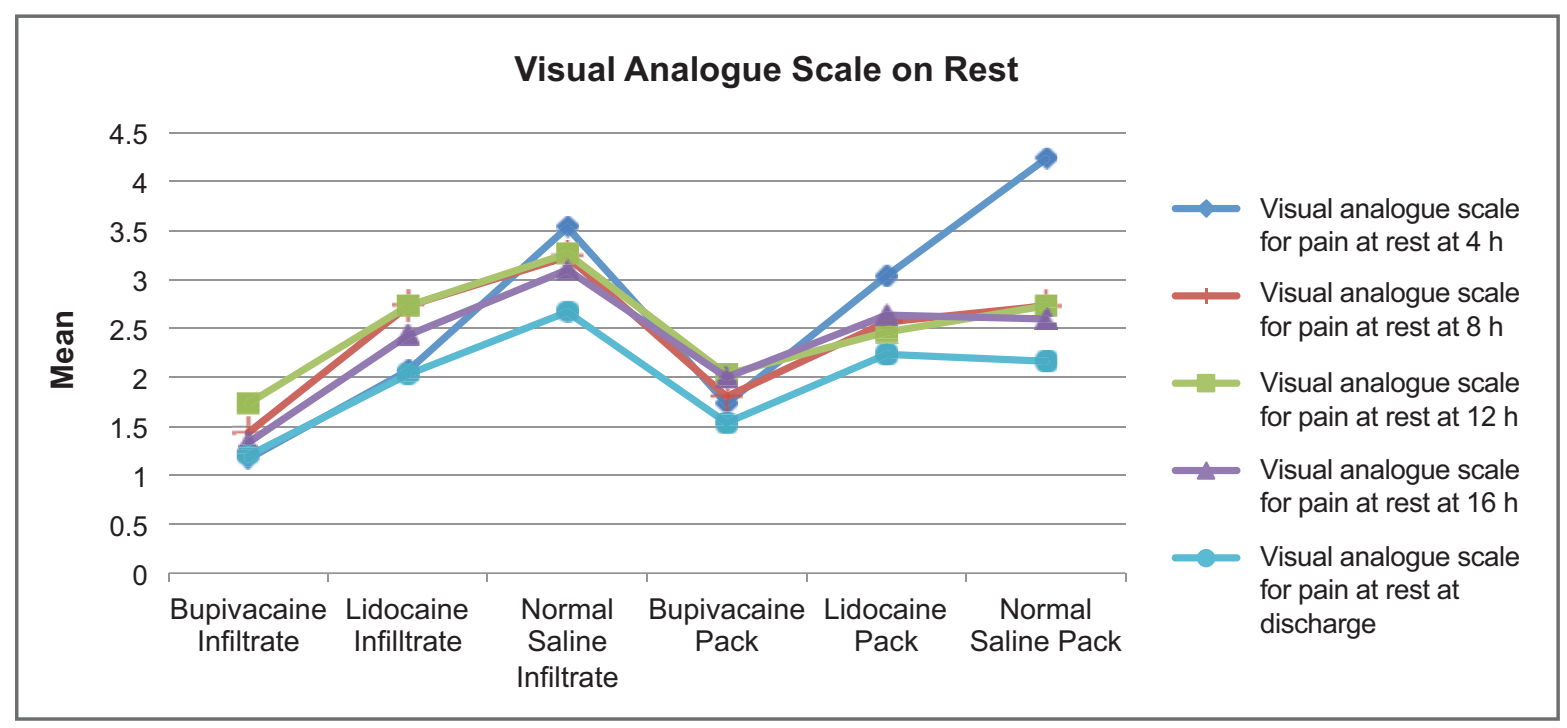

Fig. 3 Visual analogue scale for pain at rest. 
Table 4 Accumulated mean of visual analogue scale

\begin{tabular}{|l|l|l|l|}
\hline & $\begin{array}{l}\text { Difficulty in Speaking } \\
\text { (Mean } \pm \text { SD) }\end{array}$ & $\begin{array}{l}\text { Dysphagia } \\
\text { (Mean } \pm \text { SD) }\end{array}$ & $\begin{array}{l}\text { Pain at rest } \\
\text { (Mean } \pm \text { SD) }\end{array}$ \\
\hline Bupivacaine infiltrate & $1.74 \pm 0.52$ & $1.73 \pm 0.44$ & $1.37 \pm 0.27$ \\
\hline Lidocaine infiltrate & $2.47 \pm 0.43$ & $2.87 \pm 0.60$ & $2.40 \pm 0.41$ \\
\hline Normal saline infiltrate & $3.51 \pm 0.75$ & $3.71 \pm 0.87$ & $3.16 \pm 0.91$ \\
\hline Bupivacaine pack & $2.09 \pm 0.47$ & $2.57 \pm 0.59$ & $1.82 \pm 0.44$ \\
\hline Lidocaine pack & $2.84 \pm 0.63$ & $3.17 \pm 0.83$ & $2.58 \pm 0.51$ \\
\hline Normal saline pack & $3.17 \pm 0.63$ & $3.38 \pm 0.82$ & $2.89 \pm 0.76$ \\
\hline
\end{tabular}

Abbreviation: SD, standard deviation.

\section{Discussion}

The index study aimed to evaluate the effects of different local anesthetic agents and mode of delivery on postoperative pain and bleeding, and the main finding is that bupivacaine has better analgesic efficacy and could be reliably used for postoperative pain relief.

In our study, the mean pain score in the control group (normal saline infiltrate and normal saline pack) was significantly higher $(p<0.05)$ at 4 hours, 8 hours, 12 hours and 16 hours postoperatively when compared with those of patients who received bupivacaine and lidocaine (- Fig. 1 and 2). Thus, we conclude that application of bupivacaine and AU: In case lidocaine is a brand name, please, inform the name and location (city, state and country) of the manufacturer between parentheses following the brand name.is effective in the management of posttonsillectomy pain, with bupivacaine having lower scores on VAS and less requirement of analgesics in the postoperative period. This is consistent with the data published in the literature. . $^{3,13}$

It has been reported that posttonsillectomy pain is the most severe on postoperative day 1 ; then, it gradually subsides and it transiently increases at postoperative days 3 and 4 , with development of scar tissue. ${ }^{17}$ The patients included in the current study were not hospitalized for a prolonged period of time; hence, they could only be evaluated during the period in which the pain is most severe.

There is a debate in the literature regarding the efficacy of local anesthetic infiltration in the peritonsillar tissue. Several studies have demonstrated that the role of such analgesics is limited to the immediate postoperative period. ${ }^{18-22}$ Grainger et al, in a systematic review of 13 studies, concluded that local anesthetics provide modest reduction in pain associated with tonsillectomy. ${ }^{23}$ Our study shows that topical and local infiltration of bupivacaine and lidocaine provides pain relief compared with the placebo group in the immediate postoperative period.

Factors that may explain the ambiguity in the literature may be due to the surgical techniques employed during the procedure, premedication, dose and volume of local anesthetic, assessment method of the postoperative pain, and method of administration of local anesthetics. ${ }^{24}$ With the introduction of electrodissection, the risk of immediate postoperative hemorrhage is virtually non-existent. How- ever, electrodissection can lead to significant inflammation and edema resulting in pain and discomfort following surgery. ${ }^{25}$ Since our study was conducted at a single center and the surgical procedure remained consistent, the resulting effect of local anesthetics can be attributed to the anesthetic agent itself. Additionally, patients who received bupivacaine infiltration had less pain, postoperative complications and the need for additional analgesics in the immediate postoperative period.

Infiltration of local analgesic in the peritonsillar space can result in complications. Bilateral vocal cord paralysis, which can last up to 5 hours, severe upper respiratory obstruction with or without pulmonary edema due to vagal or hypoglossal blockage, life-endangering deep cervical abscess, and brain stem stroke as a result of cardiac asystole leading to tracheostomy and gastrostomy tube placement. There is an increased risk of complications if the infiltrate is deep and of higher volume of local anesthetics into the tonsillar bed. ${ }^{24,26-30}$ The majority of the patients in our study did not have any complications; however, $\sim 8 \%$ of the subjects had postoperative hemorrhagic episodes.

The limitation of our study is that subjects were not followed after discharge to observe the long-term effects of analgesics.

\section{Conclusion}

Postoperative infiltration and packing at the surgical site of bupivacaine helps in significantly reducing the pain associated with tonsillectomy. Pain severity in the bupivacaine group was significantly lower than that in the lidocaine and placebo (normal saline) groups at 4, 8, 12 and 16 hours after surgery. We advocate the use of bupivacaine infiltration or packing immediately following the procedure to achieve adequate postoperative analgesia.

Conflicts of Interest

The authors have no conflicts of interest to declare.

\section{References}

1 Bean-Lijewski JD, Kruitbosch SH, Hutchinson L, Browne B. Posttonsillectomy pain management in children: can we do better? Otolaryngol Head Neck Surg 2007;137(04):545-551 
2 Ozmen OA, Ozmen S. Topical bupivacaine compared to lidocaine with epinephrine for post-tonsillectomy pain relief in children: a randomized controlled study. Int J Pediatr Otorhinolaryngol 2011;75 (01):77-80

3 Chaturvedi S, Domkondwar UG. A comparative study of topical analgesia with $4 \%$ lignocaine and $0.5 \%$ bupivacaine following tonsillectomy. Indian J Anaesth 2005;49(02):113-115

4 Kaygusuz I, Susaman N. The effects of dexamethasone, bupivacaine and topical lidocaine spray on pain after tonsillectomy. Int J Pediatr Otorhinolaryngol 2003;67(07):737-742

5 Yilmaz S, Demiraran Y, Akkan N, et al. The effects of topical levobupivacaine on morbidity in pediatric tonsillectomy patients. Int J Pediatr Otorhinolaryngol 2009;73(09):1208-1210

6 Guntinas-Lichius O, Geißler K, Komann M, Schlattmann P, Meissner W. Inter-Hospital Variability of Postoperative Pain after Tonsillectomy: Prospective Registry-Based Multicentre Cohort Study. PLoS One 2016;11(04):e0154155

7 Spivey WH, McNamara RM, MacKenzie RS, Bhat S, Burdick WP. A clinical comparison of lidocaine and bupivacaine. Ann Emerg Med 1987;16(07):752-757

8 Goodman LS. Goodman and Gilman's the pharmacological basis of therapeutics. Vol 1549. McGraw-HillNew York1996

9 Husband AD, Davis A. Pain after tonsillectomy. Clin Otolaryngol Allied Sci 1996;21(02):99-101

10 Johansen M, Harbo G, Illum P. Preincisional infiltration with bupivacaine in tonsillectomy. Arch Otolaryngol Head Neck Surg 1996;122(03):261-263

11 Hollis LJ, Burton MJ, Millar JM. Perioperative local anaesthesia for reducing pain following tonsillectomy. Cochrane Database Syst Rev 2000;(02):CD001874

12 Goldsher M, Podoshin L, Fradis M, et al. Effects of peritonsillar infiltration on post-tonsillectomy pain. A double-blind study. Ann Otol Rhinol Laryngol 1996;105(11):868-870

13 Cakar Turhan KS, Salviz EA, Beton S, Timuroglu ST, Catav S, Ozatamer O. Peritonsillar infiltration with levobupivacaine for posttonsillectomy pain relief: does concentration have any effect? A double-blind randomized controlled clinical study. Eur Rev Med Pharmacol Sci 2015;19(07):1276-1284

14 Zhang X, Xu Y, Li P. [Effects of bupivacaine versus lidocaine infiltration on postoperative analgesia in pediatric tonsillectomy patients]. Lin Chung Er Bi Yan Hou Tou Jing Wai Ke Za Zhi 2014;28 (03): $148-150$

15 Liang H, Wang Q Cheng H, Cui X, Guo Y. Preemptive peritonsillar infiltration with lidocaine for relief of bipolar adult post-tonsillectomy pain: a randomized, double-blinded clinical study. Eur Arch Otorhinolaryngol 2013;270(12):3195-3198
16 King JT. Dangers of injections into the tonsillar fossae after tonsillectomy. Laryngoscope 1963;73(04):466-467

17 Sutters KA, Isaacson G. Posttonsillectomy pain in children. Am J Nurs 2014;114(02):36-42, quiz 43

18 Vasan NR, Stevenson S, Ward M. Preincisional bupivacaine in posttonsillectomy pain relief: a randomized prospective study. Arch Otolaryngol Head Neck Surg 2002;128(02):145-149

19 Unal Y, Pampal K, Korkmaz S, Arslan M, Zengin A, Kurtipek O. Comparison of bupivacaine and ropivacaine on postoperative pain after tonsillectomy in paediatric patients. Int J Pediatr Otorhinolaryngol 2007;71(01):83-87

20 Likar R, Morianz U, Wieser S, et al. [Pre-emptive analgesia with ropivacaine in adult tonsillectomy]. Anaesthesist 1999;48(06): 373-378

21 Nigam A, Robin PE. The role of bupivacaine in post-tonsillectomy pain. Clin Otolaryngol Allied Sci 1991;16(03):278-279

22 Park AH, Pappas AL, Fluder E, Creech S, Lugo RA, Hotaling A. Effect of perioperative administration of ropivacaine with epinephrine on postoperative pediatric adenotonsillectomy recovery. Arch Otolaryngol Head Neck Surg 2004;130(04):459-464

23 Grainger J, Saravanappa N. Local anaesthetic for post-tonsillectomy pain: a systematic review and meta-analysis. Clin Otolaryngol 2008;33(05):411-419

24 Nikandish R, Maghsoodi B, Khademi S, Motazedian S, Kaboodkhani R. Peritonsillar infiltration with bupivacaine and pethidine for relief of post-tonsillectomy pain: a randomised double-blind study. Anaesthesia 2008;63(01):20-25

25 Leach J, Manning S, Schaefer S. Comparison of two methods of tonsillectomy. Laryngoscope 1993;103(06):619-622

26 Elhakim M, Ali NM, Rashed I, Riad MK, Refat M. Dexamethasone reduces postoperative vomiting and pain after pediatric tonsillectomy. Can J Anaesth 2003;50(04):392-397

27 Fradis M, Goldsher M, David JB, Podoshin L. Life-threatening deep cervical abscess after infiltration of the tonsillar bed for tonsillectomy. Ear Nose Throat J 1998;77(05):418-421

28 Tajima K, Sato S, Miyabe M. A case of acute pulmonary edema and bulbar paralysis after local epinephrine infiltration. J Clin Anesth 1997;9(03):236-238

29 Bean-Lijewski JD. Glossopharyngeal nerve block for pain relief after pediatric tonsillectomy: retrospective analysis and two cases of life-threatening upper airway obstruction from an interrupted trial. Anesth Analg 1997;84(06):1232-1238

30 Ozkiriş M, Kapusuz Z, Saydam L. Comparison of ropivacaine, bupivacaine and lidocaine in the management of post-tonsillectomy pain. Int J Pediatr Otorhinolaryngol 2012;76(12): 1831-1834 